of the uterus by Victor Bonney, cancer of the intestines by C. A. R. Nitch, malignant tumours of the kidney by R. H. J. Swan, of the bladder by Swift Joly, and of the rectum by W. E. Miles, are of great value and interest both in their pathological and clinical aspects.

As noted by the Editor, the lectures are given as delivered, in spite of the fact that there are occasional divergences of opinion. For example Leitch says that "it is unsafe to argue that the mammary gland in chronic mastitis is any more liable to become cancerous than the apparently normal breast," while Sampson Handley in his lecture remarks that "chronic mastitis is undoubtedly-and in my opinion beyond controversyone of the predisposing causes of malignant disease."

The Editor leaves it to the reader to decide "what is truth," and in this case we concur with the surgeon.

These lectures, ably composed, and presented in a well produced and illustrated volume, are worth study by both pathologists and clinicians.

\section{PHYSIOLOGY OF THE CENTRAL NERVOUS SYSTEM} AND SPECIAL SENSES.-By N. J. Vazifdar, L.M. \& S., F.C.S., F.C.P.S. Fourth Edition. Bombay: S. Govind \& Co., 1925. Pp. 238, with 26 illustrations. Price, Rs. 4-8-0.

THE first edition of Dr. Vazifdar's “Physiology of the Central Nervous System and Special Senses" was published in 1911 and the fourth edition has now appeared.

The book is intended for students of physiology preparing for the medical degree examination. The fact that it is compiled from the best known text-books on the subject-Halliburton's "Handbook of Physiology," Howell's "Text-book of Physiology," Schäfer's “ Essentials of Histology," Stewart's "Handbook of Physiology," Starling's "Principles of Human Physiology," Short's "New Physiology in Surgical and. General Practice," etc., is sufficient guarantee of the quality of the contents. Being a resume the book is useful to students and practitioners for revision and reference purposes. There are numerous diagrams and tabular statements which help not only in grasping the facts, but in remembering them. The popularity of the book is well deserved.

HEALTH AND PSYCHOLOGY OF THE CHILD.Edited by Elizabeth Sloan Chesser, M.D. London: William Heinemann (Medical Books), Ltd., 1925. Pp. 302. Price, 7s. 6d. net.

MoDern psychology is prolific nowadays in new publications. This book, however, is a new departure in that it appeals to those who have the physical and mental welfare of the child at heart. To parents, teachers, members of the medical profession and all religious instructors it is a highly commendable book, as its several chapters have all the stamp of authority, being written by men and women whose names recall to one's mind the subject with which they deal. Tredgold devotes a chapter on deliquency in children; Leonard Williams on the endocrine glands and vitamines; Lady Baden-Powell on the value of training; Percy Hall on the value of sunlight on children; Viscountess Erleigh on mothercraft, etc. The book is "all-embracing" in its handling of the subject, and as a perusal of its contents will indicate, the subject is approached from many standpoints.

In a chapter on "the physical aspects of adolescence" by Sir Bruce Bruce-Porter, the following occurs:"There is no doubt the nations of the world who are the most powerful in physique and peaceful in mind are the non-meat eating races and so in the animal world. The animals that do the heavy work are cereal feeders, while the nervous nations and nervous animals are the carnivorous." I believe many distinguished medical men, such as Lieut.-Col. McCay, Lieut.-Col. McCarrison, I.M.S., and Professor Mellanby of Sheffield would dispute such a statement.

Again he states "........... even cancer may be traced to this chronic poisoning (neglect of the bowel)".
This very probable hypothesis regarding the cause of cancer cannot, I believe, be accepted as a scientific fact.

As an introduction to the study of mental phenomena by analytical or psycho-analytical means the study of the child mind is undoubtedly the simplest. 'This book is therefore commended to all those who have a baby or children to experiment with, and a highly interesting experiment it is bound to be if the thoughts expressed and the principles laid down are taken to heart.

THE CEREBRO-SPINAL FLUID IN CLINICAL DIAGNOSIS.-By J. Godwin Greenfield, M.D., B.Sc., M.R.C.P. and E. A. Carmichael, M.B., Ch.B. London: Macmillan \& Co., Ltd., 1925. Pp. 272. Price, 12s. net.

THIS is a comprehensive and well arranged work dealing with the characters, normal and abnormal, of the cerebro-spinal fluid, and with its anatomical and physiological relationships.

There are also sections detailing the alterations encountered in certain diseases, and the technique employed in various methods of examination.

The authors write with the authority of their special experience in the National Hospital for the Paralysed and Epileptic in London and have produced a valuable work of .reference for physicians and laboratory workers.

A good list of references to books and special articles is included.

\section{"BILHARZIA:" A PAPER FOR THE PRACTITIONER.} -By F. Gordon Cawston, M.D. (Cantab.). London: John Bale, Sons \& Danielsson, Ltd., 1925. Pp. 20. Price, 2s. 6d. net.

THIs little booklet, which is a reprint from a paper in the Journal of Tropical Medicine and Hygiene, gives a brief account of Bilharzia disease as it occurs in South Africa, laying particular emphasis on the points which are of interest to the general practitioner.

After a few preliminary pages on the occurrence of the disease, the method of infection and the life cycle of the parasite, the author briefly describes the principal symptoms and pathological conditions associated with the disease, and then devotes most of the remaining half of the article to treatment. Only one course of treatment is described, and the details of the technique are made almost childishly simple, so that any practitioner, however inexperienced, could hardly make a mistake if he followed directions. If one is to judge the technical ability of the practitioners for whom the book is written by the completeness of these instructions then it would seem that the short paragraph on the complement-fixation test which follows is so inadequate as to be practically worthless." For these readers, also, it seems that a more thorough description of the ova and method of recognising them, even at the expense of some of the description of the cercarix, would have been useful.

\section{PREPARATION OF SCIENTIFIC AND TECHNICAL PAPERS.-By Sam F. Trelease and Emma Sarepta Yule. Baltimore: Williams \& Wilkins Co., 1925. English Agents: Messrs. Bailliere, Tindall \& Cox, London. Pp. 113. Price, 7s. 6d. net.}

THIs book was written for the benefit of the senior student and the scientist who has had little practice in putting the result of his work on paper. If it were compulsory for every contributor to a scientific journal to read a book such as the one under review, much of the editors' time would be saved. The book was not written particularly for the medical man but the advice given is almost all applicable to papers on medical subjects. An attempt is made to show the reader how he should put his ideas on paper, how he should arrange them in the form of a balanced paper and how he should rearrange his paper and correct his mistakes. 
Valuable information on the use and abuse of capital letters and italics is given. There is a section on the letters and methods of literature citarter of the whole book and goes into the matter very thoroughly. Three different goes into the miven. It is not very apparent what differmethods are given. It is not very ap third method and ence exists between the siticised. The third method is, the methods are not critich is generally accepted as being I think, the ontical. A list of abbreviations for wellthe most practical. A liven. This list is very incomplete. I feel that it would have been better to have made the list more complete, even if this meant a considerable list more of the volume, or, as an alternative, increase in the size of the principles which govern these a short discussion on have been more useful than an abbreviations would have on proof reading is disincomplete list. The section that proofs should be read appointing; the suggestion that prod line by line with through three times being compared line by line with the original is not very helpful. Mistakes are much more likely to be noticed if the paper is read through slowly and intelligently, reference only the original in the case of figures. The method might be followed for the first reading only, especially when the proof reader is unfamil hints about subject-matter of the paper. A few und have been usethe common tricks of compositor missing from a word, ful ; for example, if a letter is missing there is usually a very fair chance that the in the next letter line.

information in the book but there is much that has been left out. I cannot help feeling that we have not quite received our money's worth. LEMENTARY ANATOMY AND PHClay, M.D., Ch.B., NURSES.-BY H. Clifford B.S.E. Third Edition. M.R.C.S., L.R.C.P., F.R.C.S.E. 1924. Pp. X plus London: Bailliere, Tind the text. Price, 12s. net.

THIS book is an honest attempt to make anatomy and physiology interesting and intelligible for nurses during We cannot but feel, however, that the their training. We can that the chapters on embryotext is too discursive, anatomy, psychology, and the logy, comparative anato average nurse can be emotions are more than

\section{CHININUM Presented by Bureau tot Bevordering van het Kinine Gebruik, 48 De Wittenkade, Amsterdam.}

THus little book, designed to popularise the use of quinine in various conditions apart from malaria, is a collection of articles by various authors on the adminicollection of alue of quinine in certain diseases.

It also contains a series of 24 heliotypes on cinchona culture in Java.

In an early chapter the action of quinine is lucidly Incribed by Professor H. Kionka, of the University described section is well worth reading by the of Jena. This as well as the practising physician.

It should be a work of great interest to the student and practitioner of medicine as it brings home to one that the medicinal uses of quinine are not confined to its use in malaria.

AN AFRICAN HOLIDAY.-By Richard L. Sutton, M.D. C. V. Mosby Co., 1924. LL.D. St. Louis: The C.

THis little book is a fascinating story of the author's experiences in Africa shooting big game. It is clearly and simply written and fully illustrated with actua and simply written and lovers of Nature.

\section{Annual Reports.}

ANNUAL, REPOR'T ON THE JAIPUR MEDICAL INSTITUTIONS FOR 1923. BY DALJANG SINGH KHANKA, M.B., RAI BAHADUR. SUPERINTENDENT OF DISPENSARIES AND VACCINATION, JAIPUR.

THERE were 2,982 births as against 4,122 deaths in Jaipur city during the year, but the actual death rate, 34.28 per mille, is very similar to that of most Indian towns. More than half the mortality occurred among children of less than five years of age. Small-pox was mildly epidemic during the year and caused 106 deaths, December being the month in which the incidence was greatest. From September to December Jaipur was stricken with dengue, and five emergency sub-assistant surgeons were specially deputed to go round their circles morning and evening, treating cases and issuing instructions for anti-mosquito measures. Plague, influenza and cholera were fortunately absent during the year. "The sanitary condition of the city was in the same deplorable state as in previous years" writes Dr. Khanka; "so nothing more need be said about it"; he hopes, however, that the newly appointed Municipal Board will take steps to deal with it. An interesting feature of the report is that $60 \mathrm{mad} \operatorname{logs}$, captured inside the city during the year, were taken far away into the jungles and there liberated. The number of vaccinations carried out shewed a satisfactory increase, some 23 per mille of the population being vaccinated annually.

Twenty-nine hospitals and dispensaries were at work during the year and treated 2,31,824 out-patients and 5,403 in-patients. At the Mayo Hospital a large volume of surgical work was carried out during the year, eye work and operations for vesical calculus being especially prominent. Litholapaxy was carried out on 56 patients with only 1 death, and an analysis is given of the results. The duration of symptoms varied from 1 day to 3 years, the average time for the operation was some 20 minutes, and the largest stone dealt with weighed 1,230 grains. The average stay of these patients in hospital was only 4.69 days.

\section{PAS'TEUR INSTITUTE OF SOU'THERN INDIA,} COONOOR. ANNUAL REPOR'T FOR THE YEAR 1923-24. BY LIEUTENAN'T-COLONEL J. W. CORNWALL, M.A., M.D., I.M.S. MADRAS: SUPERIN'TENDENT, GOV'T. PRESS. 1924.

THE most striking feature in this report is the tremendous decrease in the number of patients treated at Coonoor, owing to the extended issue of the anti-rabic vaccine to government headquarter hospitals. Only 1,354 patients were treated at Coonoor, as compared with 3,375 for the previous year; whilst the numbers treated outside Coonoor rose for the same period from 1,248 to 3,692 . The total number of patients treated with the Coonoor vaccine during the year, on adding up the above figures, shews the usual annual increase, 5,046 in 1923-24, as against 4,623 in 1922-23.

The vaccine is issued from Coonoor in sealed ampoules, and it is of some interest to compare the results of institutional treatment at Coonoor with those of treatment elsewhere. It had been anticipated that a considerable number of the patients treated at hospitals would fail to complete the course of treatment, but this has proved not to be the 'case; only 3.5 per cent. failed to attend daily for the complete course of treatment. On the other hand, it has proved exceedingly difficult to get in the desired reports and returns; information as to results could not be obtained with regard to no less than 40 per cent. of patients treated at hospitals. As a result the statistics for the Institute are not strictly comparable with those for patients treated elsewhere: at the former the total hydrophobia incidence was 0.29 per cent. among the 60 per cent. of those treated outside about 